\title{
Anti-retinal autoantibodies in experimental ocular and systemic toxoplasmosis
}

\author{
Justus G. Garweg • Yvonne de Kozak • \\ Brigitte Goldenberg • Matthias Boehnke
}

Received: 24 May 2009/Revised: 25 October 2009/Accepted: 2 November 2009/Published online: 3 December 2009

(C) Springer-Verlag 2009

\begin{abstract}
Background Patients with ocular toxoplasmosis (OT) develop autoreactivity to several retinal antigens, including retinal S-antigen. By establishing an experimental rabbit model of systemic and of primary and secondary ocular toxoplasmosis, we wished to investigate the onset and development of humoral response to retinal S-antigen. Methods Of twelve infection-naïve rabbits, six were left untreated, and the other six were infected subcutaneously
\end{abstract}

\section{J. G. Garweg $(\bowtie)$}

Swiss Eye Institute,

Bremgartenstrasse 119,

$\mathrm{CH}$ - 3012 Bern, Switzerland

e-mail: justus.garweg@swiss-eye-institute.com

\section{J. G. Garweg}

Medical Faculty, University of Bern,

Bern, Switzerland

Y. de Kozak · B. Goldenberg

Physiopathology of Ocular Diseases, Therapeutic Innovations, Institut National de la Santé et de la Recherche Médicale, UMR S 872, Team 17,

Paris, France

\section{Y. de Kozak · B. Goldenberg}

Centre de Recherche des Cordeliers,

Université Pierre et Marie Curie,

UMR S 872,

Paris, France

Y. de Kozak • B. Goldenberg

Université Paris Descartes,

UMR S 872,

Paris, France

\section{Boehnke}

Institute of Ophthalmology,

Rothenbaumchaussee 123 ,

20149 Hamburg, Germany with 5,000 tachyzoites of the highly virulent, non-cystforming BK-strain of Toxoplasma gondii. Three months later, the left eye of each animal was infected transvitreally with 5,000 tachyzoites of the same strain. The right eye of each rabbit served as an uninfected control. Blood and aqueous humor were collected prior to infection, and up to 90 days thereafter. Using the ELISA technique, all samples were analyzed in parallel for total $\mathrm{IgG}$, and antibodies against toxoplasmic, bovine retinal S-antigen and peptide 35 from human S-antigen.

Results In infection-naïve rabbits Toxoplasma-specific antibodies were detected 10 to 15 days after systemic and ocular infection. Serum antibodies against retinal S-antigen and peptide 35 were not detected in response to systemic Toxoplasma infection. After ocular challenge, aqueoushumour levels of antibodies against retinal S-antigen and peptide 35 in the infected eye began to rise 10 to 15 days later in infection-naïve, but not in infection-immunized animals. During the early post-infection period, the concentrations of anti-retinal antibodies in the infected eye correlated with the severity of inflammatory tissue destruction, but returned to baseline later even though the inflammatory response persisted. In the uninfected partner eye, concentrations of anti-retinal and toxoplasmic antibodies did not correlate with each other.

Conclusion Our data afford no evidence of similarities between toxoplasmic and retinal antigens, nor of infectioninduced humoral autoimmunity. They indicate rather that retinal autoantigens are liberated in the context of inflammatory tissue destruction due to ocular toxoplasmosis.

Keywords Toxoplasma gondii - Toxoplasmosis · Ocular toxoplasmosis · Retinochoroiditis - Chorioretinitis ·

Autoimmunity · ELISA · Retinal S-antigen · Animal experiments $\cdot$ Animal model $\cdot$ Aqueous humor 


\section{Introduction}

Patients with ocular toxoplasmosis (OT) are known to develop autoreactivity to retinal antigens, such as the Stype. However, the contribution of this antibody production to the OT pathology is not clear [1-7]. That autoimmune processes do indeed play a pathophysiological role in OT is evidenced by the greater prevalence of anti-Toxoplasma gondii antibodies in patients with non-toxoplasmic endogenous uveitis than in healthy individuals [8]. On the other hand, autoimmunity against retinal antigens can develop also in patients with retinal detachment and diabetic retinopathy, as well as in those with autoimmune diseases in which the eye is not involved [9]. Cells that have been derived from patients with Fuchs' anterior uveitis without evident retinal disease present a positive cellular response to the retinal S-antigen compared to healthy controls [10].

According to current opinion, OT may be capable of inducing autoimmunity in the context of an infectionassociated immunopathological process [11]. The autoimmune disease could be precipitated by at least one of three basic influences, namely by genetic [12], environmental [13-16] or immunoregulatory factors [17-19].

The immunopathological response could evolve at either a cellular $[1,2,20]$ or an humoral antigen-driven level $[3,4$, 6]. In a murine model of OT, the destruction of retinal tissue is effected mainly by an infiltration of mononuclear cells [21]. Whether autoimmune phenomena are involved also in the development of recurrences is still unclear [22]. In experimental toxoplasmic encephalitis, chronic disease is associated with a maturation and prolonged activity of dendritic cells $[23,24]$, which could thus well be involved in its recurrences.

An infectious agent may predispose an individual to, or actually precipitate autoimmune reactions by unmasking sequestered autoantigens against cells that have been induced to express class-II HLA antigens in response to the underlying infection. On the other hand, the parasite may be comprised of proteins that share an antigenic similarity with human retinal antigens, thereby rendering it capable of inducing an autoimmune reaction against ocular proteins, as is the case in herpetic keratitis [25-27]. The disruption of the ocular vascular barrier that follows the infectious and inflammatory destruction of ocular tissue may propagate the accumulation and binding of anti-retinal autoantibodies, and exacerbate the destruction of tissue [7]. Interestingly, naturally-occurring anti-retinal antibodies have been detected in healthy individuals who have no history of ocular disease $[7,28,29]$. Autoimmune reactivity in OT could represent an unspecific epiphenomenon of retinal damage, in conjunction with a secondary, parasite-induced release of antigens.

By drawing on an experimental rabbit model of systemic and primary and secondary ocular toxoplasmosis [30], we wished to investigate the onset and development of the humoral response to the retinal S-antigen, using an established autoantibody ELISA technique [31-33]. A comparison between primary ocular and systemic toxoplasmosis will reveal whether any cross-reactivity exists between toxoplasmal and retinal antigens, and that between primary and secondary OT will disclose whether a correlation exists between the levels of anti-retinal antibodies and the degree of ocular tissue destruction.

\section{Materials and methods}

Protocol of rabbit infection with virulent BK strain of Toxoplasma gondii tachyzoites

All animal experiments were approved by the local and institutional Animal Ethics Committee, and were performed in accordance with ARVO's Guidelines for Animal Research under the surveillance of the local Public Veterinary Health authorities. Experimental ocular toxoplasmosis was induced either as a primary disease in infection-naïve rabbits or as a secondary one in infection-immunized animals by the intraocular injection of tachyzoites of the highly virulent BK strain of Toxoplasma gondii, as previously described [30]. Twelve 4-month-old seronegative Dutch belt rabbits of both sexes, weighing 3.5 to $5 \mathrm{~kg}$, were used in this study. They were obtained from a local breeder and housed in an animal-keeping unit at the University of Bern. Six of the rabbits were left untreated until the time of ocular infection. Each of the other six rabbits was infected subcutaneously with 5,000 tachyzoites of the virulent, non-cyst-forming BK-strain of Toxoplasma gondii. Between 8 and 28 days later, they were injected intramuscularly with clindamycin $(20 \mathrm{mg} / \mathrm{kg}$ of body weight/day) to prevent a lethal course of events. Nevertheless, two of the six rabbits died. A 3-month period was then allowed for the infection to quieten down. At the end of this period, the left and the right eyes of the rabbits in each group were fundoscopically examined after pupillary dilatation to exclude the presence of any ocular pathology. The left eye of the four infection-immunized and of the six infection-naïve rabbits was then infected transvitreally with 5,000 tachyzoites of the BK-strain of Toxoplasma gondii under indirect ophthalmoscopic control. The right eye of each rabbit served as an uninfected control. Between 8 and 28 days later, all animals were intramuscularly injected with clindamycin (to prevent a lethal course of events). The rabbits were examined regularly. Samples of blood from the ear vein and of aqueous humor from both eyes were collected under conditions of general anaesthesia, both prior to systemic or ocular infection (day " 0 "), and on days $5,10,15,21,28,35,42,60,72$ and 90 . All samples were 
processed immediately as described below. They were then stored at $-20^{\circ} \mathrm{C}$ until required for the antibody analyses, which were run in parallel.

\section{Methods}

Collection and preparation of samples $150-$ to $250-\mu 1$ aliquots of aqueous humor were collected by puncturing the anterior chamber with a 30-gauge needle, which was connected to a tuberculin syringe. Each sample was centrifuged immediately after its collection. The sediment was used for the amplification of DNA (data not presented) and the supernatant for the antibody analysis. Samples of blood were withdrawn from the ear vein. They were clotted and centrifuged to yield the serum, which was also used for the antibody analysis.

Total rabbit $\operatorname{Ig} G$ This was quantified using the ELISA technique. A triplicate set of controls with a known antibody concentration was run in parallel with the test samples on each test plate to internally equilibrate the system. The test samples were run in duplicate, and the average measurement was used for subsequent calculations. As outlined in a previous study report [34], we attempted to quantify not only IgG but also IgM and IgA, but none of these were sufficiently specific to permit their unique determination without binding to rabbit $\mathrm{IgG}$, so running the corresponding analyses was judged not useful.

Anti-Toxoplasma rabbit $\operatorname{Ig} G$ This was also quantified using the ELISA technique. For this purpose, tachyzoites of Toxoplasma gondii that had been killed by freezing and thawing were employed, as previously described [34]. To detect the local production of antibodies, the cut-off level for the Goldmann-Witmer coefficient (antibody ratio C) was arbitrarily set at $\mathrm{C} \geq 3$.

The level of antibodies against the retinal S-antigen and peptide 35 were similarly quantified using the enzymelinked immunosorbent assay (ELISA) technique [32, 33]. Since peptide 35 is a major epitope in the $\mathrm{S}-\mathrm{Ag}$ molecule,
Fig. 1 Concentrations of total $\mathrm{IgG}$ in the serum and aqueous humour of rabbits that had been infected with 5000 tachyzoites of the BK strain of Toxoplasma gondii. a Primary systemic toxoplasmosis. b Primary OT. c Secondary OT a

Primary Systemic Toxoplasmosis

- Total IgG -

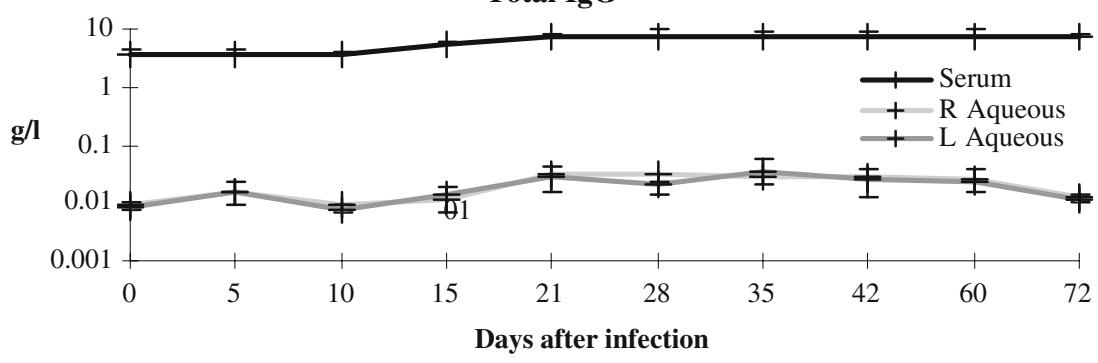

b

Primary Ocular Toxoplasmosis

- Total IgG -

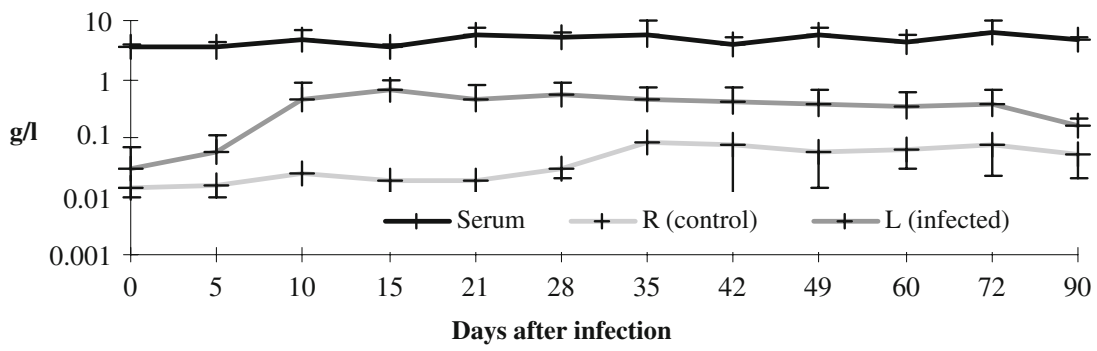

C Secondary Ocular Toxoplasmosis

- Total IgG -

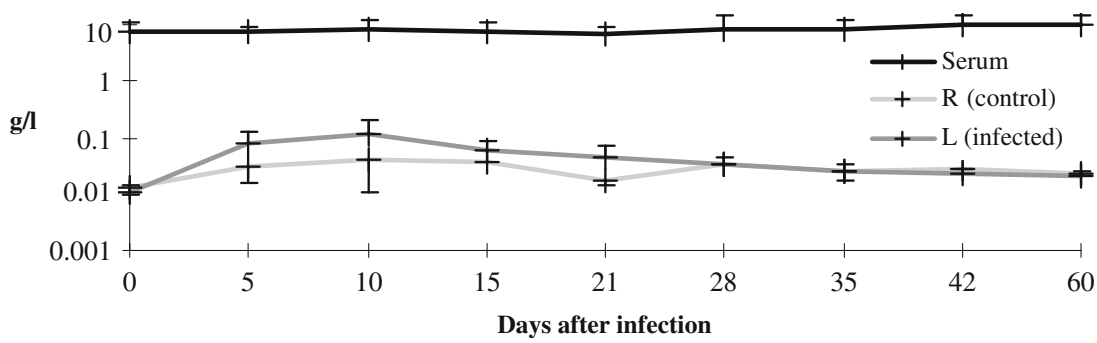


and since there is a sequence homology between peptide 35 from rabbit, rat and human, we checked the antibody response to both, the entire bovine $\mathrm{S}-\mathrm{Ag}$ molecule and to peptide 35 in toxoplasmic rabbits.

Briefly, microtiter 96-well plates (Nunc-immuno plate, Roskilde, Denmark) were coated with retinal S-antigen $(2 \mu \mathrm{g} / \mathrm{ml})$ and peptide $35(2 \mu \mathrm{g} / \mathrm{ml} ; 35)$. Serum and aqueous humor samples of each rabbit were added to the wells at dilution $1 / 50$. Serial dilutions between $\mathrm{I} / 20$ to $1 / 1000$, of rat sera with high antibody titers to S-Ag followed by incubation with horseradish peroxidase-conjugated goat anti-rat $\operatorname{IgG}(\mathrm{H}+\mathrm{L})$, and of randomly selected test rabbit sera and aqueous humor samples, were included in each assay to validate the sensitivity and the variation of the ELISA. The dilution 1/50 was chosen since no background was detected at this dilution. Since we had to titrate numerous samples of blood and aqueous humors, and to avoid variations between the plates, we incubated the plates coated with dilutions of samples overnight and processed for antibody titration all the plates at the same time the day
Fig. 2 Concentrations of antiToxoplasma-specific IgG in the serum and aqueous humour of rabbits that had been infected with 5000 tachyzoites of the BK strain of Toxoplasma gondii. a Primary systemic toxoplasmosis. b Primary OT. c Secondary OT a

\section{Primary Systemic Toxoplasmosis}

- anti -Toxoplasma-specific IgG -
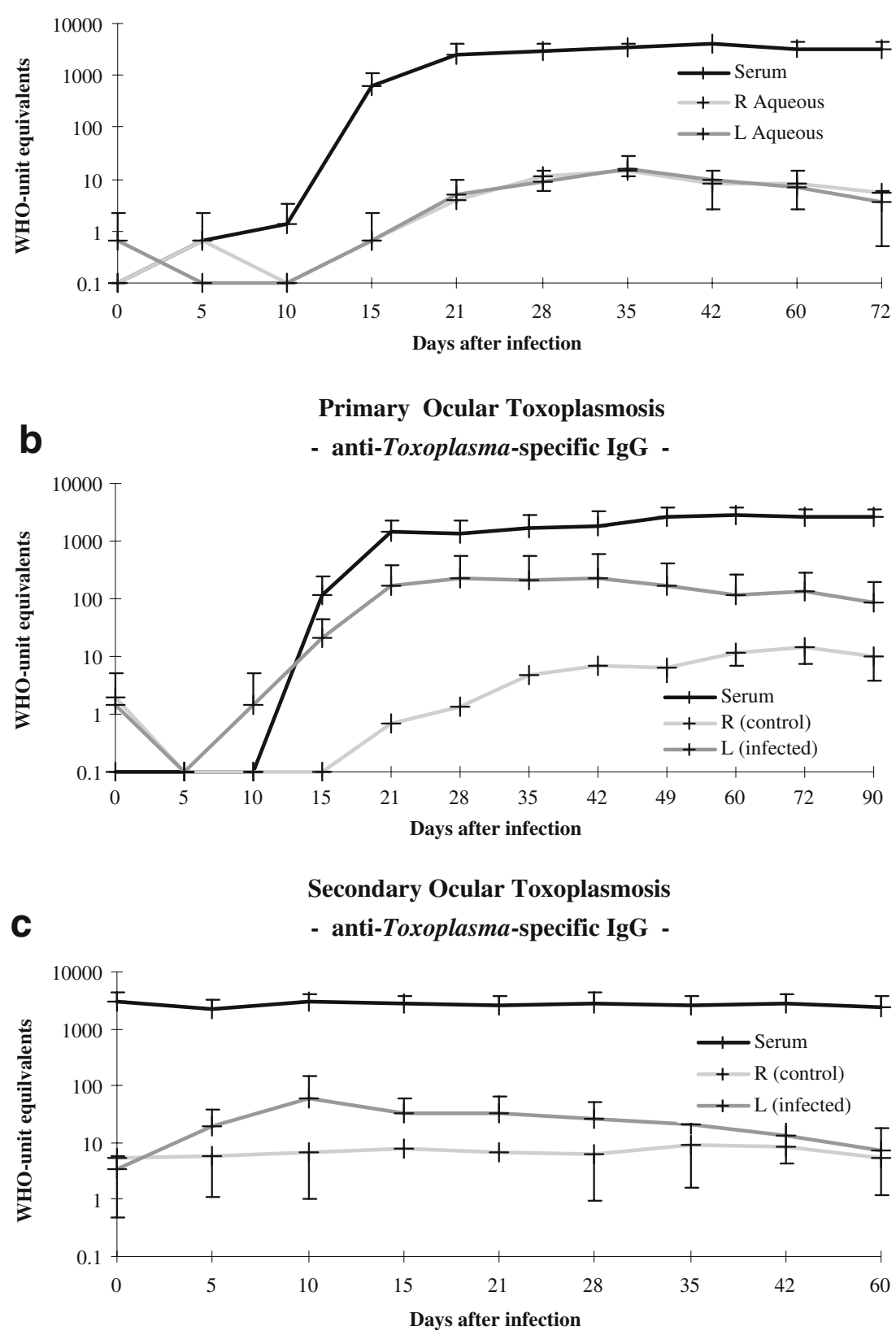
after. Results were not different for samples which had been incubated for 2 hours or overnight. After incubation overnight at $4^{\circ} \mathrm{C}$ to allow antibody to bind antigen, the samples were removed and the wells were washed. Bound antibody was detected with horseradish peroxidase-conjugated goat antirabbit $\operatorname{IgG}(\mathrm{H}+\mathrm{L} ; 1 / 1000$ diluted) (Zymed Laboratories, San Francisco, CA, USA) and application of $O$-phenylenediamine substrate in $0.1 \mathrm{M}$ citrate buffer (Sigma, L'Isle D'Abeau 219 Chesnes, France). Absorbance was read at $490 \mathrm{~nm}$, and mean optical density (OD) \pm SD was calculated for each group. Data are represented as median, minimal and maximal values, together with the standard deviation. For the statistical analysis (Student's $t$-test), the data were assumed to be normally distributed. Since the number of samples was limited, the level for statistical significance was set at $p<0.01$.

\section{Results}

Despite prophylactic treatment with clindamycin, only eight out of 12 rabbits (four of the six with primary systemic toxoplasmosis and four of the six with primary ocular
Fig. 3 Concentrations of antiretinal S-antigen-specific IgG in the serum and aqueous humour of rabbits that had been infected with 5000 tachyzoiotes of the BK strain of Toxoplasma gondii. a Primary systemic toxoplasmosis. b Primary OT. c Secondary OT
Primary Systemic Toxoplasmosis

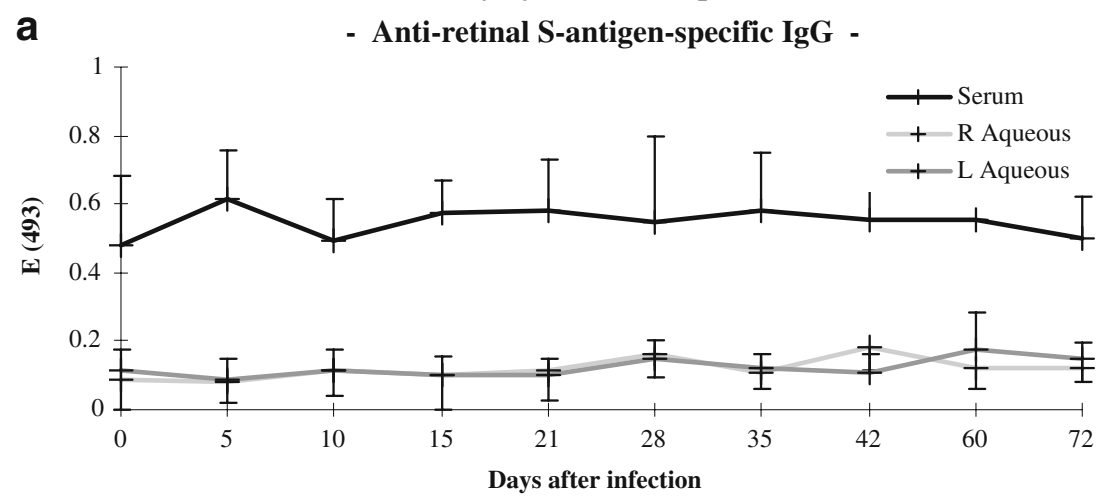

Primary Ocular Toxoplasmosis

b - Anti-retinal S-antigen-specific IgG -

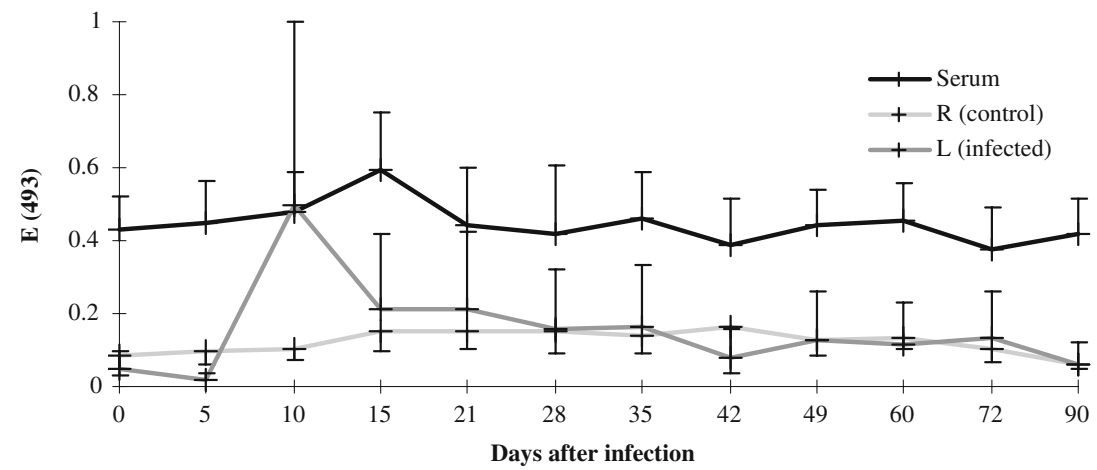

Secondary Ocular Toxoplasmosis

C - Anti-retinal S-antigen-specific IgG -

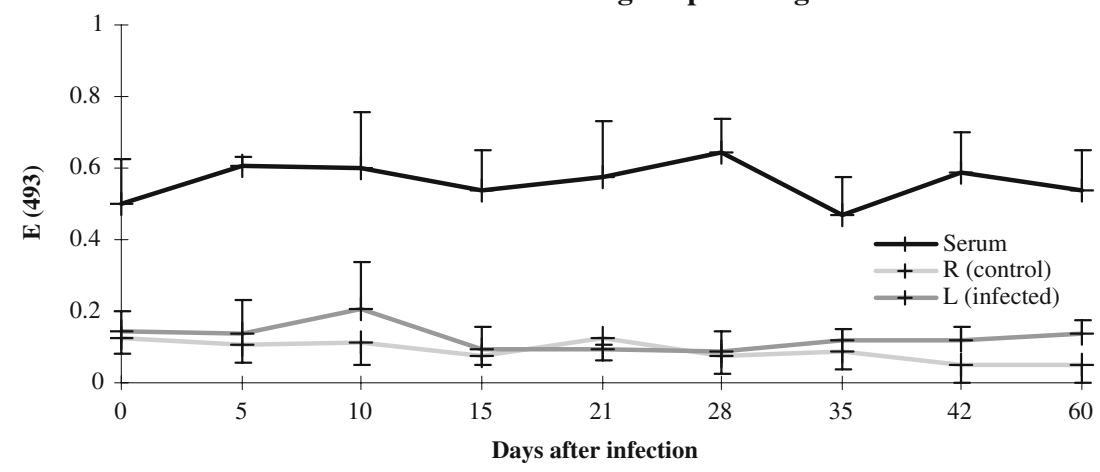


toxoplasmosis (OT) survived the infection with Toxoplasma until day 90 . Hence, the group of animals with secondary OT consisted of four rabbits.

In Figs. 1, 2, 3 and 4, temporal changes in the concentrations of total IgG (Fig. 1), of Toxoplasma-specific IgG (Fig. 2), of retinal S-antigen-specific IgG (Fig. 3) and of retinal p35-antigen-specific IgG (Fig. 4) are depicted for the rabbits with primary systemic toxoplasmosis (Figs. 1a, 2a, 3a and 4a), with primary OT (Figs. 1b, 2b, 3b and 4b), and with secondary OT (Figs. 1c, 2c, 3c and 4c). These sets of data were used to calculate the antibody coefficients for Toxoplama-specific IgG (Fig. 5), for retinal S-antigen- specific IgG (Fig. 6) and for retinal p35-antigen-specific IgG (Fig. 7) in each disease category: primary systemic toxoplasmosis (Figs. 5a, 6a and 7a), primary OT (Figs. 5b, 6b and 7b) and secondary OT (Figs. 5c, 6c and 7c).

The systemic injection of rabbits with Toxoplasma elicited a twofold increase of levels of total IgG in the serum and aqueous humor (Fig. 1a).

This rise indicates that a humoral immune response had been stimulated. Ocular infection with Toxoplasma elicited an increase in the local level of total IgG (Fig. 1b and c), which may reflect the stimulation of a local humoral immune response and/or a breakdown of the blood ocular
Fig. 4 Concentrations of antiretinal p35-antigen-specific IgG in the serum and aqueous humour of rabbits that had been infected with 5000 tachyzoiotes of the BK strain of Toxoplasma gondii. a Primary systemic toxoplasmosis. b Primary OT. c Secondary OT

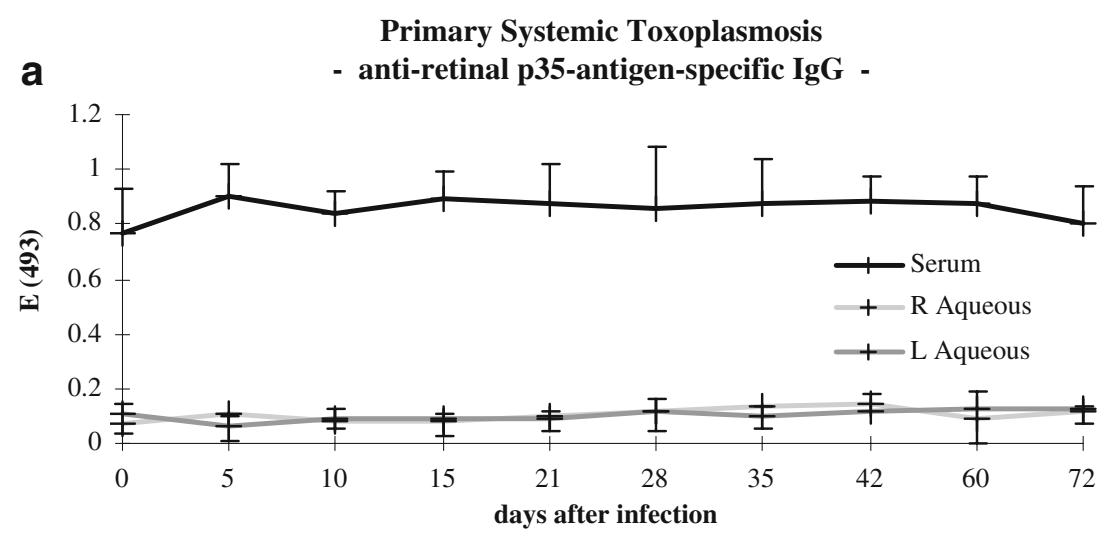

Primary Ocular Toxoplasmosis

b - anti-retinal p35-antigen-specific IgG -

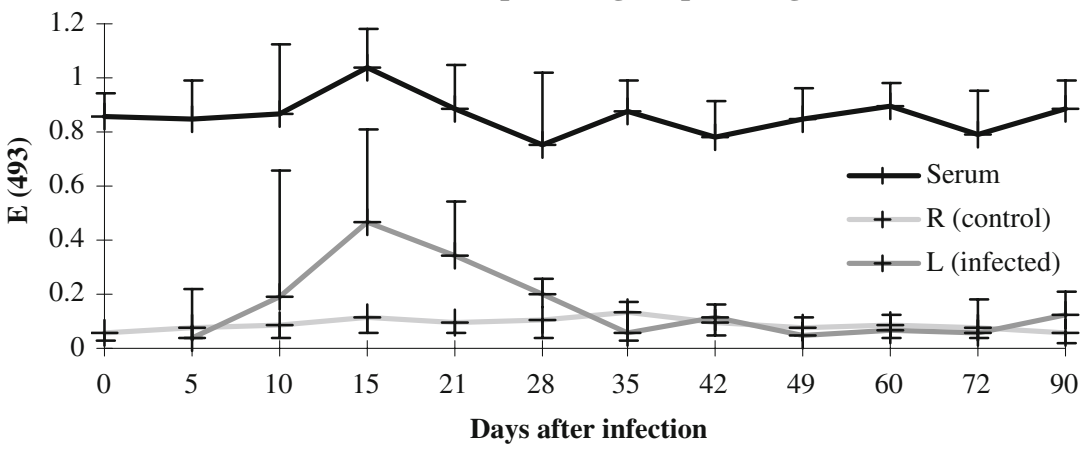

Secondary Ocular Toxoplasmosis

C - anti-retinal p35-antigen-specific IgG -

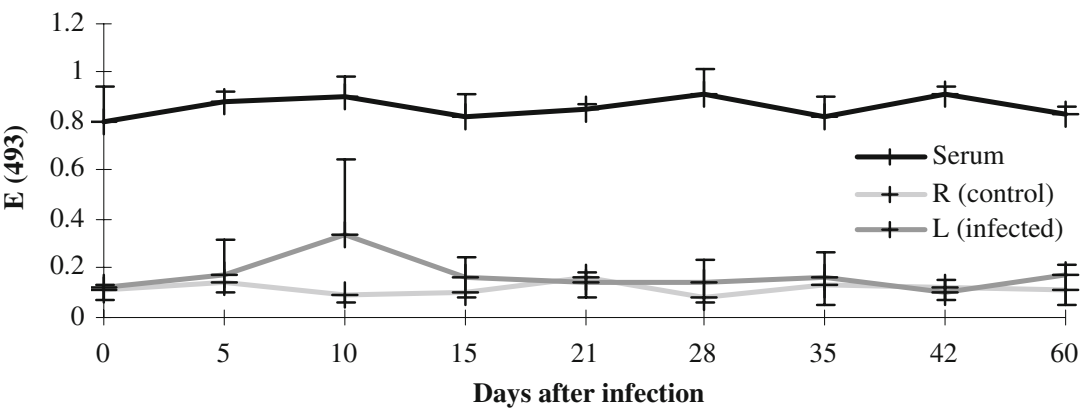


Fig. 5 Antibody (GoldmannWitmer) coefficients for Toxoplasma-specific IgG in rabbits that had been infected with tachyzoites of the BK-strain of Toxoplasma gondii. a Primary systemic toxoplasmosis. b Primary OT. c Secondary OT
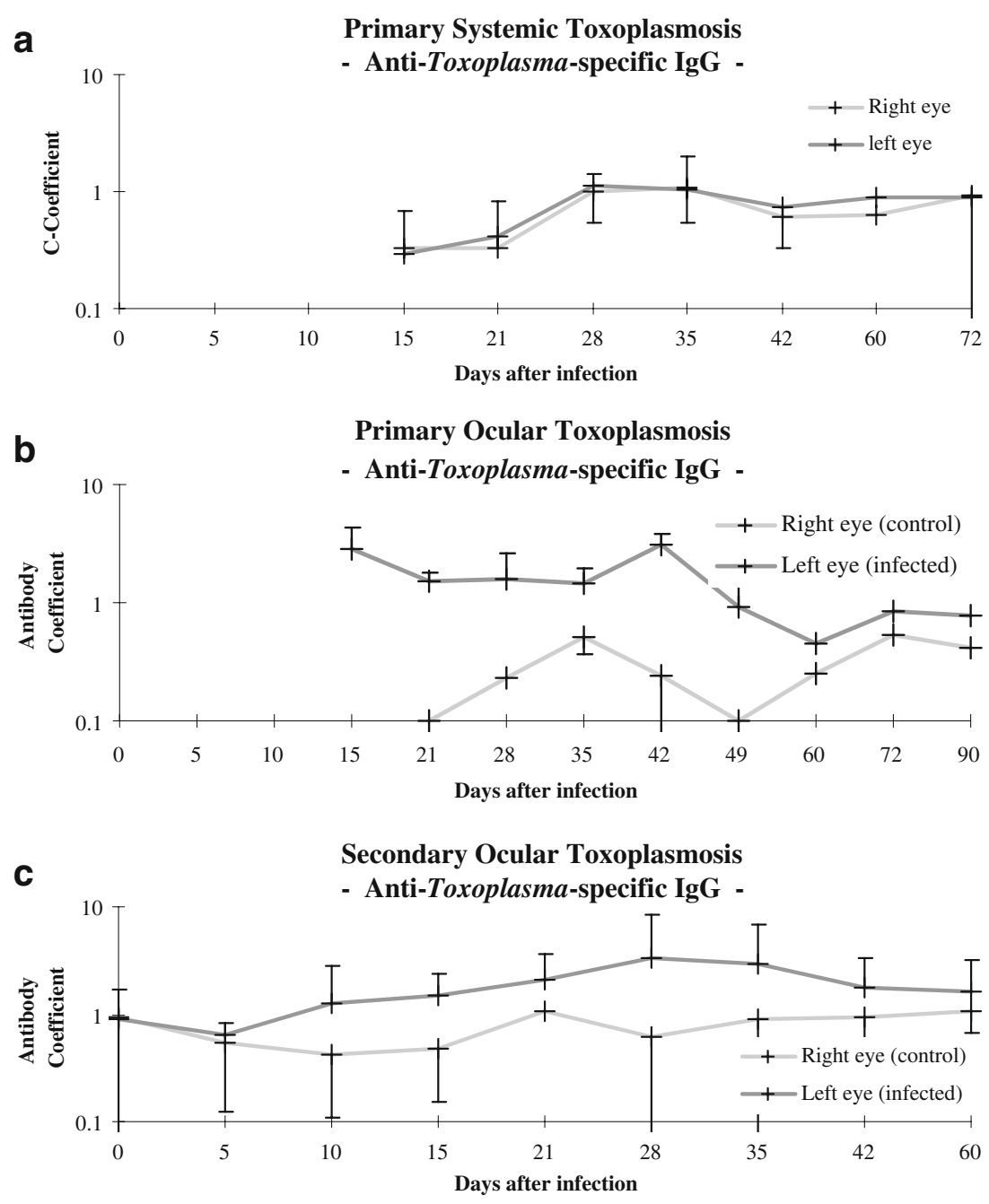

barrier. The time-lapse that was required for the production of antibodies was 10 to 15 days (Fig. $2 b$ and c), which is consistent with previously published data [33]. In infectionimmunized animals, intravitreal reinfection with Toxoplasma did not induce any change in the serum antibody levels, which is in accordance with the situation in humans. However, in the infected eye, the local level of Toxoplasmaspecific IgG increased (Fig. 2c).

Infection with Toxoplasma did not elicit any change in the serum levels of antibodies against the retinal S-antigen and peptide 35 . Looking at individual response, there is a delayed increase of serum levels of anti-S-Ag. Presence of low concentrations of specific IgG to S-antigen and peptide 35 is constitutively detected in the serum at day 0 in all groups of rabbits, but not in the aqueous humor when the blood-ocular barrier is intact. The local levels of antibodies against the retinal antigens increased after 10 to 15 days in an interindividually highly variable fashion in the infected eye of the infection-naïve, but not (or to a lesser extent), again in an interindividually highly variable fashion, in that of infection-immunized rabbits (Figs. 3 and 4). A local synthesis of anti-retinal antibodies has to be anticipated, since an elevation of specific $\operatorname{IgG}$ to $\mathrm{S}$-antigen and peptide 35 in aqueous humor was found in the infected eye of the infection-naïve and infection-immunized rabbits, whereas no such antibodies were detected in the uninfected eye.

The antibody coefficient $\mathrm{C}$ for Toxoplasma in the infected eye reached levels above 2 after 15 to 42 days in rabbits with primary OT, and after 28 to 48 days in those with secondary OT. These levels were never reached in any of the animals with systemic toxoplasmosis (Fig. 5). An antibody coefficient of 3 or more was never consistently achieved in any of the animals, which is in accordance with previously published data [34].

In animals with systemic toxoplasmosis, the antibody coefficients in the infected eye for the retinal S-antigen and for peptide 35 rose non-significantly from day 42 after the systemic infection. In animals with primary or secondary OT, the antibody coefficients in the infected eye tended to drop during the early post-infection phase and then to 
Fig. 6 Antibody (GoldmannWitmer) coefficients for retinal S-antigen-specific $\mathrm{IgG}$ in rabbits that had been infected with tachyzoites of the BK-strain of Toxoplasma gondii. a Primary systemic toxoplasmosis. b Primary OT. c Secondary OT
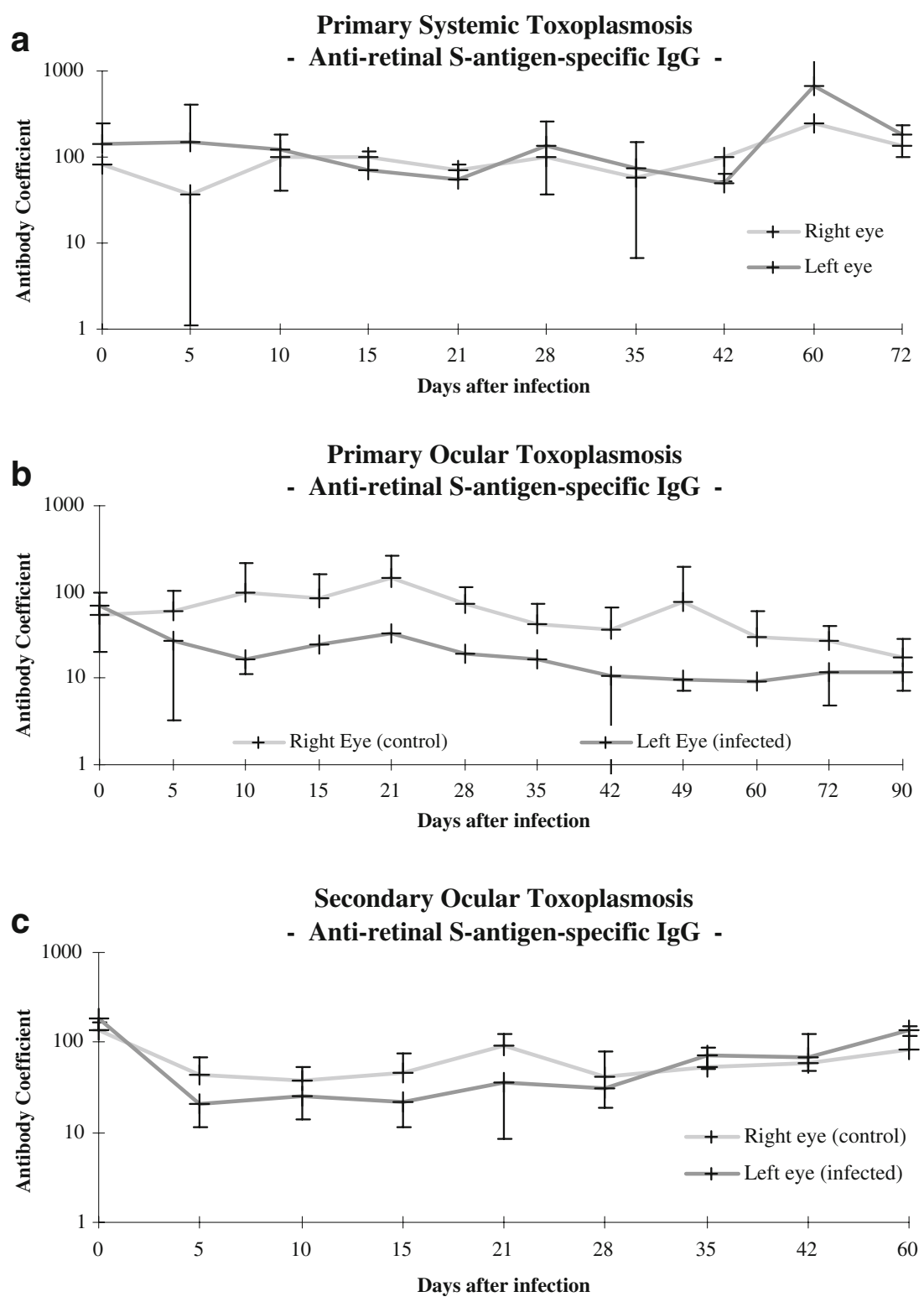

recover (Figs. 6 and 7), but were always lower than in the non-infected eye. This may either reflect a wash-out of these antibodies in consequence of the blood-ocular barrier breakdown or a binding of antibodies to (liberated as well as tissue-bound) local retinal antigens. Interestingly, the antibody coefficient for anti-retinal antibodies was more than 10-fold higher than those for the Toxoplasma-specific antibodies. However, owing to the high standard deviations, the differences were not consistently significant $(p<0.01)$ The rabbits used in this study were not congenic, which may explain the inconstistancy of the results between individual rabbits (Fig. 8a and b show this exemplarily for the group of primary ocular toxoplasmosis). These results suggest either that the humoral immune response against retinal antigens is a more localized phenomenon than that against toxoplasmal antigens, or that the response to Toxoplasma infection is not a strictly compartmentalized event, even after ocular challenge.

\section{Discussion}

Using an experimental rabbit model of systemic and ocular toxoplasmosis [33], and an established autoantibody ELISA technique $[32,33]$, we demonstrated that the concentrations of anti-retinal antibodies increased in the infected eyes during the early post-infection period. The data correlated with the degree of infectious tissue destruction at the clinical level (data not presented). In the uninfected partner eyes, the concentrations of anti-retinal antibodies did not 
Fig. 7 Antibody (GoldmannWitmer) coefficients for retinal p35-antigen-specific IgG in rabbits that had been infected with tachyzoites of the BKstrain of Toxoplasma gondii. a Primary systemic toxoplasmosis. b Primary OT. c Secondary OT

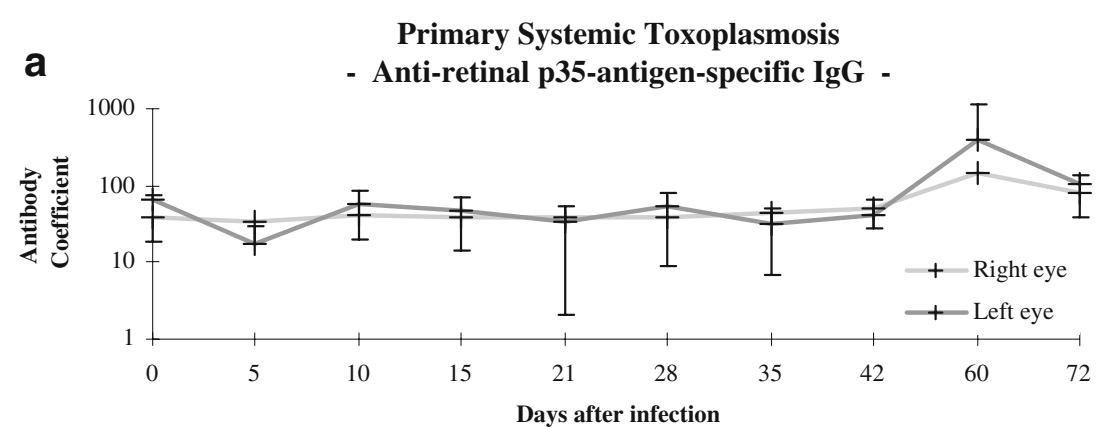

Primary Ocular Toxoplasmosis

b - Anti-retinal p35-antigen-specific IgG -

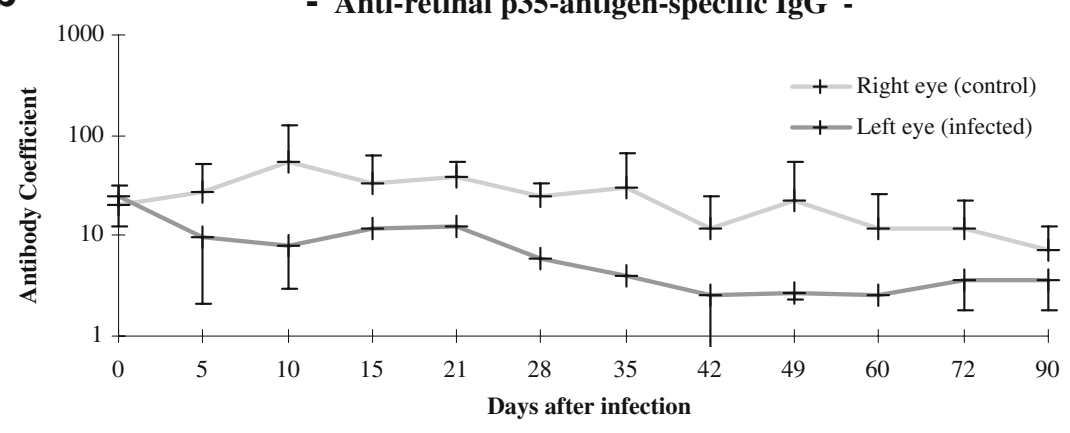

Secondary Ocular Toxoplasmosis

C - Anti-retinal p35-antigen-specific IgG -

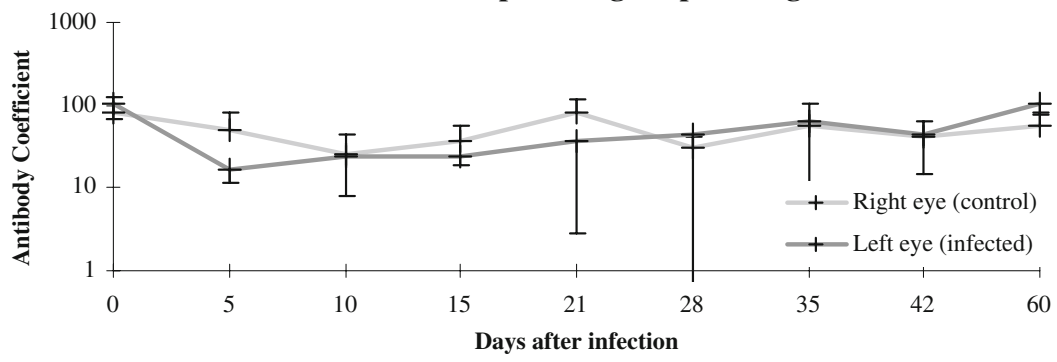

rise, and no tissue destruction was observed. The fact that the partner eye did not respond with antiretinal antibody production strongly argues against an infection-induced autoimmune response to retinal antigens. Hence, this would be expected to evolve bilaterally. Instead, the antibodies may have been induced locally in response to the retinal lesioning. The concentrations of anti-retinal antibodies failed to increase after the systemic infection of rabbits with Toxoplasma. This finding indicates that the causes for retinal and toxoplasmic antigen synthesis are distinct. In rabbits with either primary or secondary OT, the levels of the anti-retinal antibodies were restored to baseline levels during the later post-infection period, even though the inflammatory infiltration of the anterior chamber, of the vitreous and of the intraocular tissues persisted. Moreover, the clinically observed degree of tissue destruction did not parallel the levels of anti-Toxoplasma antibodies. Hence, our data offer no support for the existence of an infection- induced humoral autoimmune response that is based upon a cross-reactivity between toxoplasmic and retinal antigens [6]. They suggest rather that retinal autoantigens are liberated in the context of inflammatory tissue destruction [20]. On the other hand, in mice that have been infected with Toxoplasma gondii in utero, retinal vasculitis develops, as well as the almost uniform and highly-selective destruction of the photoreceptor layer. These share features in common with experimental autoimmune retinitis [36, 37].

The precise pathogenic role of retinal autoimmune responses in eye disease is unknown [38]. The humoral autoimmune response may be no more than an epiphenomenon which develops after damage to the retina by either physical agencies, micro-organisms, or immunological impairment [39, 40]. And even if autoimmunity does not itself initiate ocular inflammation, it might perpetuate and sustain the inflammatory state, and thereby exacerbate the tissue damage [9]. In our study, the quantitative disparity 
Fig. 8 Concentrations of antiretinal S-antigen-specific (a) and anti-p35.specific (b) IgG in the aqueous humour and serum of single rabbits (PO1-PO6) that had primarily been infected in the left eye with 5,000 tachyzoites of the BK strain of Toxoplasma gondii
Primary Ocular Toxoplasmosis

a Anti-retinal S-antigen-specific IgG in the infected eye

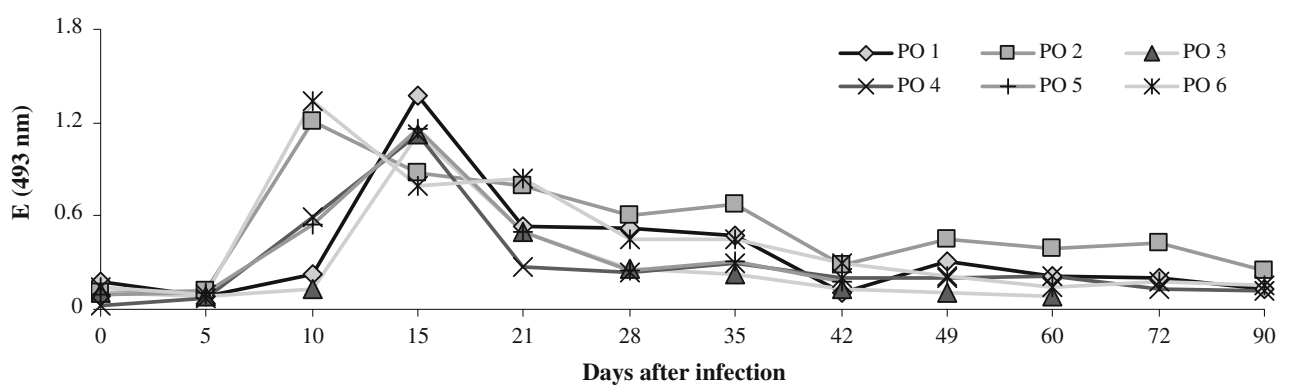

Primary Ocular Toxoplasmosis

b Anti-retinal p35-antigen-specific IgG in the infected eye

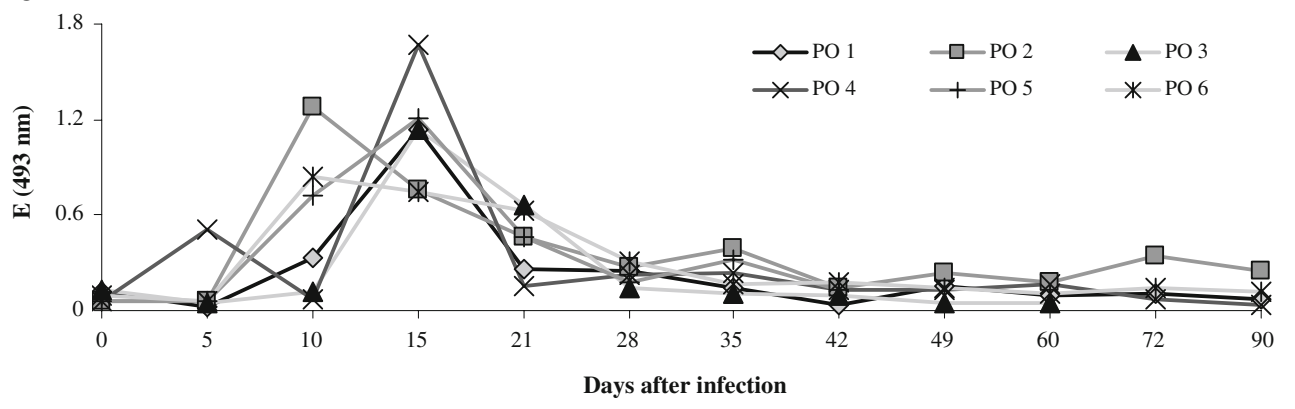

and the temporal asynchrony in the evolution of anti-retinal and anti-Toxoplasma antibodies suggest that humoral autoimmunity might well develop as an epiphenomenon in the context of inflammatory tissue destruction [19]. However, the levels of autoantibodies that are produced in consequence of the infectious tissue destruction may not be sufficient to yield evidence of permanent parasite-induced autoreactivity [6, 38].

Our data do not permit the drawing of any conclusions relating to autoimmunity at the cellular level and the interrelation between cellular and humoral immune response [41]. Interestingly, it has been reported that in the eyes of horses with equine recurrent uveitis, both IgG antibodies and autoreactive T-cells specific for retinal antigens were detected [42]. The role of infectious agents at the origin of the autoimmune response to retinal autoantigens has remained less clear [42]. In addition, the analysis of certain serum markers during equine recurrent uveitis has shown that serum is a valuable tool for analysing the onset and possible recurrences of the disease [43].

T-cells that have been derived from the peripheral blood of patients with mild OT react more strongly to retinal autoantigens than do those that have been derived from individuals with a more aggressive form of the disease [6, 38]. Exogenous, non-self antigens can stimulate type- $2 \mathrm{~T}$ helper cells, and thereby modify the cytokine environment sufficiently to alter the cytokine phenotype of inflammatory, autoreactive T-cell clones $[41,44]$. This response may afford the host some protection against experimental autoimmune encephalitis and possibly other T-cell-mediated autoimmune diseases. Hence, infection with Toxoplasma could even protect the host against the development of overt autoimmune diseases at immuno-privileged sites such as the eye and the brain [44]. Outside the retina, anti-retinal antigens could help in the development of peripheral tolerance, as well as in protecting the host against autoimmunity [45]. The result may be the consequence of conflicting cellular immune responses [46]. In OT, as in more overt autoimmune diseases, the cellular immune response is mediated by type- 1 T-helper cells. Consequently, the cytokine profiles may be similar in each case, but tailored to suit the pathogenic agency [46, 47]. Such tailoring might explain why the autoimmune response is lower in OT than in autoimmune diseases [48].

Our own study suffered from two major drawbacks. Firstly, some interesting information may have been lost due to the smallness of the animal cohort, which precluded a rigorous statistical evaluation of the data. Secondly, the generally poor specificity of anti-rabbit antibodies precluded a quantification of specific $\operatorname{IgM}, \operatorname{IgA}$ and $\operatorname{IgE}$ antibodies. A hypersensitivity reaction to Toxoplasma antigens or an autoimmune response against retinal autoantigens could conceivably contribute to the clinical disease [2, 49, 50], although IgE antibodies are not usually detected [51]. In OT, the degree of anti-retinal reactivity correlates not only with the concentrations of antibodies against the retinal S-antigen, but also with those of antibodies against the interphotor- 
eceptor binding protein [52] and other retinal antigens [39, 40]. Interestingly, the antibody coefficients for retinal autoantigens were consistently more than 10 -fold higher than those for toxoplasmic antigens. This finding reconfirms the assumption that the local production of an antibody parallels the strictly local availability of the corresponding antigen. Moreover, the antibody coefficients tended to be lower in the infected than in the uninfected eye. This finding may be accounted for by a breakdown of the uveovascular barrier and the ensuing dispersal of the antibodies.

In conclusion, our data indicate that at the humoral level, infection-induced immunopathological rather than autoimmune phenomena contribute to the inflammatory response in OT, and that the latter do not influence the clinical evolution of the disease.

Acknowledgement This study was generously supported by the Swiss National Science Foundation (grant no. 32-32757.91).

Part of the experiments and data presented in this article were done while one of the authors (JGG) was affiliated to the Department of Ophthalmology at the University of Bern, Switzerland.

\section{References}

1. Nussenblatt RB, Gery I, Ballintine EJ, Wacker WB (1980) Cellular immune responsiveness of uveitis patients to retinal Santigen. Am J Ophthalmol 89:173-179

2. Wyler DJ, Blackman HJ, Lunde MN (1980) Cellular hypersensitivity to toxoplasmal and retinal antigens in patients with toxoplasmal retinochoroiditis. Am J Trop Med Hyg 29:1181-1186

3. Gregerson DS, Abrahams IW, Thirkill CE (1981) Serum antibody levels of uveitis patients to bovine retinal antigens. Invest Ophthalmol Vis Sci 21:669-680

4. Abrahams IW, Gregerson DS (1982) Longitudinal study of serum antibody responses to retinal antigens in acute ocular toxoplasmosis. Am J Ophthalmol 93:224-231

5. Abrahams IW, Gregerson DS (1983) Longitudinal study of serum antibody responses to bovine retinal S-antigen in endogenous granulomatous uveitis. Br J Ophthalmol 67:681-684

6. Kijlstra A, Hoekzema R, vd Lelij A, Doekes G, Rothova A (1990) Humoral and cellular immune reactions against retinal antigens in clinical disease. Curr Eye Res 9(Suppl):85-89

7. Whittle RM, Wallace GR, Whiston RA, Dumonde DC, Stanford MR (1998) Human antiretinal antibodies in toxoplasma retinochoroiditis. Br J Ophthalmol 82:1017-1021

8. Holliman RE, Stevens PJ, Duffy KT, Johnson JD (1991) Serological investigation of ocular toxoplasmosis. Br J Ophthalmol 75:353-355

9. Rahi AH, Addison DJ (1983) Autoimmunity and the outer retina. Trans Ophthalmol Soc UK 103:428-437

10. La Hey E, Broersma L, van der Gaag R, Baarsma GS, Rothova A, Kijlstra A (1993) Does autoimmunity to S-antigen play a role in Fuchs' heterochromic cyclitis? Br J Ophthalmol 77:436-439

11. Dumonde DC, Kasp-Grochowska E, Banga JP, Sanders MD, Graham E, Stanford MA, Faure JP, De Kozak Y, Van Tuyen V (1985) Autoimmune mechanisms in inflammatory eye disease. Trans Ophthalmol Soc UK 104:232-238

12. Garweg JG, Ventura AC, Halberstadt M, Silveira C, Muccioli C, Belfort RJ, Jacquier P (2005) Specific antibody levels in the aqueous humor and serum of two distinct populations of patients with ocular toxoplasmosis. Int J Med Microbiol 295:287-295

13. Glasner PD, Silveira C, Kruszon-Moran D, Martins MC, Burnier Júnior M, Silveira S, Camargo ME, Nussenblatt RB, Kaslow RA, Belfort Júnior R (1992) An unusually high prevalence of ocular toxoplasmosis in southern Brazil. Am J Ophthalmol 114:136-144

14. Radon K, Dressel H, Windstetter D, Reichert J, Schmid M, Nowak D (2003) Toxoplasma gondii infection, atopy and autoimmune disease. Eur J Med Res 8:147-153

15. de Amorim Garcia CA, Oréfice F, de Oliveira Lyra C, Gomes AB, França M, de Amorim Garcia Filho CA (2004) Socioeconomic conditions as determining factors in the prevalence of systemic and ocular toxoplasmosis in Northeastern Brazil. Ophthalmic Epidemiol 11:301-317

16. Portela RW, Bethony J, Costa MI, Gazzinelli A, Vitor RW, Hermeto FM, Correa-Oliveira R, Gazzinelli RT (2004) A multihousehold study reveals a positive correlation between age, severity of ocular toxoplasmosis, and levels of glycoinositolphospholipid-specific immunoglobulin A. J Infect Dis 190:175-183

17. Deckert-Schluter M (1998) Rudolf-Virchow Prize 1998. Award lecture. Toxoplasmosis: a model infection for studying systemic and intracerebral immune reactions. Verh Dtsch Ges Pathol 82:9-22

18. Yamamoto JH, Vallochi AL, Silveira C, Filho JK, Nussenblatt RB, Cunha-Neto E, Gazzinelli RT, Belfort R Jr, Rizzo LV (2000) Discrimination between patients with acquired toxoplasmosis and congenital toxoplasmosis on the basis of the immune response to parasite antigens. J Infect Dis 181:2018-2022

19. Vallochi AL, Nakamura MV, Schlesinger D, Martins MC, Silveira C, Belfort R Jr, Rizzo LV (2002) Ocular toxoplasmosis: more than just what meets the eye. Scand J Immunol 55:324-328

20. Vallochi AL, da Silva Rios L, Nakamura MV, Silveira C, Muccioli C, Martins MC, Belfort R Jr, Rizzo LV (2005) The involvement of autoimmunity against retinal antigens in determining disease severity in toxoplasmosis. J Autoimmun 24:25-32

21. Dutton GN (1986) The causes of tissue damage in toxoplasmic retinochoroiditis. Trans Ophthalmol Soc UK 105:404-412

22. O'Connor GR (1983) Factors related to the initiation and recurrence of uveitis. XL Edward Jackson memorial lecture. Am J Ophthalmol 96:577-599

23. Fischer HG, Bonifas U, Reichmann G (2000) Phenotype and functions of brain dendritic cells emerging during chronic infection of mice with Toxoplasma gondii. J Immunol 164:4826-4834

24. Fischer HG, Reichmann G (2001) Brain dendritic cells and macrophages/microglia in central nervous system inflammation. J Immunol 166:2717-2726

25. Wickham S, Carr DJ (2004) Molecular mimicry versus bystander activation: herpetic stromal keratitis. Autoimmunity 37:393-397

26. Benoist C, Mathis D (2001) Autoimmunity provoked by infection: how good is the case for T cell epitope mimicry? Nat Immunol 2:797-801

27. Deshpande SP, Lee S, Zheng M, Song B, Knipe D, Kapp JA, Rouse BT (2001) Herpes simplex virus-induced keratitis: evaluation of the role of molecular mimicry in lesion pathogenesis. $\mathrm{J}$ Virol 75:3077-3088

28. Forrester JV, Stott DI, Hercus KM (1989) Naturally occurring antibodies to bovine and human retinal $\mathrm{S}$ antigen: a comparison between uveitis patients and healthy volunteers. Br J Ophthalmol $73: 155-159$

29. Kasp E, Whiston R, Dumonde D, Graham E, Stanford M, Sanders M (1992) Antibody affinity to retinal S-antigen in patients with retinal vasculitis. Am J Ophthalmol 113:697-701

30. Garweg JG, Kuenzli H, Boehnke M (1998) Experimental ocular toxoplasmosis in naive and primed rabbits. Ophthalmologica 212:136-141

31. Doekes G, Luyendijk L, Gerritsen MJ, Kijlstra A (1992) Anti-retinal S-antigen antibodies in human sera: a comparison of reactivity 
in ELISA with human or bovine S-antigen. Int Ophthalmol 16:147152

32. Stiemer RH, Gausepohl H, Mirshahi M, de Kozak Y, Kraft M, Faure JP, Frank RW (1992) Immunological characterization of an immunomodulatory epitope in S-antigen/arrestin with a sequence motif common to tumor necrosis factor alpha. Immunol Lett 32:233240

33. de Kozak Y, Stiemer RH, Mirshahi M, Frank RW, de Smet M, Faure JP (1992) Humoral immune response against the Santigen/TNF alpha common epitope in rat EAU suppressed by the monoclonal antibody S2D2. Curr Eye Res 11(Suppl):119127

34. Garweg JG, Boehnke M (2006) The antibody response in experimental ocular toxoplasmosis. Graefes Arch Clin Exp Ophthalmol 244:1668-1679

35. de Smet MD, Bitar G, Mainigi S, Nussenblatt RB (2001) Human S-antigen determinant recognition in uveitis. Invest Ophthalmol Vis Sci 42(13):3233-3238

36. Lee WR, Hay J, Hutchison WM, Dutton GN, Siim JC (1982) A murine model of congenital toxoplasmic retinochoroiditis. Acta Ophthalmol (Copenh) 61:818-830

37. Hay J, Lee WR, Dutton GN, Hutchison WM, Siim JC (1984) Congenital toxoplasmic retinochoroiditis in a mouse model. Ann Trop Med Parasitol 78:109-116

38. Vallochi AL, Nakamura MV, Schlesinger D, Martins MC, Silveira C, Belfort R Jr, Rizzo LV (2002) Ocular toxoplasmosis: more than just what meets the eye. Scand J Immunol 55:324-328

39. Nussenblatt RB, Mittal KK, Fuhrman S, Sharma SD, Palestine AG (1989) Lymphocyte proliferative responses of patients with ocular toxoplasmosis to parasite and retinal antigens. Am J Ophthalmol 107:632-641

40. Muino JC, Juarez CP, Luna JD, Castro CC, Wolff EG, Ferrero M, Romero-Piffiguer MD (1999) The importance of specific IgG and $\mathrm{IgE}$ autoantibodies to retinal $\mathrm{S}$ antigen, total serum $\mathrm{IgE}$, and $\mathrm{SCD} 23$ levels in autoimmune and infectious uveitis. J Clin Immunol 19:215222
41. de Smet MD, Chan CC (2001) Regulation of ocular inflammationwhat experimental and human studies have taught us. Prog Retin Eye Res 20:761-797

42. Deeg CA, Kaspers B, Gerhards H, Thurau SR, Wollanke B, Wildner G (2001) Immune responses to retinal autoantigens and peptides in equine recurrent uveitis. Invest Ophthalmol Vis Sci 42:393-398

43. Zipplies JK, Hauck SM, Schöffmann S, Amann B, van der Meijden CH, Stangassinger M, Ueffing M, Deeg C (2009) Kininogen is decreased in peripheral blood stream but increased in target tissue of autoimmune uveitis. Invest Ophthalmol Vis Sci Aug 20. [Epub ahead of print]

44. Falcone M, Bloom BR (1997) A T helper cell 2 (Th2) immune response against non-self antigens modifies the cytokine profile of autoimmune $\mathrm{T}$ cells and protects against experimental allergic encephalomyelitis. J Exp Med 185:901-907

45. Gregerson DS (2002) Peripheral expression of ocular antigens in regulation and therapy of ocular autoimmunity. Int Rev Immunol 21:101-121

46. Graham AL (2002) When T-helper cells don't help: immunopathology during concomitant infection. Q Rev Biol 77:409-434

47. Garweg JG, Candolfi E (2009) Immunopathology in ocular toxoplasmosis: facts and clues. Mem Inst Oswaldo Cruz 104:211-220

48. Radon K, Dressel H, Windstetter D, Reichert J, Schmid M, Nowak D (2003) Toxoplasma gondii infection, atopy and autoimmune disease. Eur J Med Res 8:147-153

49. Burns RM, Rheins MS, Suie T (1967) Anti-DNA in the sera of patients with uveitis. Arch Ophthalmol 77:777-779

50. O'Connor GR (1970) The influence of hypersensitivity on the pathogenesis of ocular toxoplasmosis. Trans Am Ophthalmol Soc 68:501-547

51. Liotet S, Bloch-Michel E, Petithory JC, Batellier L, Chaumeil C (1992) Biological modifications of the vitreous in intraocular parasitosis: preliminary study. Int Ophthalmol 16:75-80

52. Hoekzema R, Hwan SB, Rothova A, van Haren MA, Donoso LA, Kijlstra A (1990) Serum antibody response to human and bovine IRBP in uveitis. Curr Eye Res 9:1177-1183 